\title{
Método Reno: uma proposta para análise comportamental do discurso
}

\author{
The Reno Method: a proposal for the behavioral analysis of discourse \\ Método Reno: una propuesta para el análisis conductual del discurso
}

Giovanna Silveira Xavier ${ }^{1}$, Priscila Sampaio Espíndola², Lucas Ferraz Córdova ${ }^{3}$, Nayla Nara Ferreira Mota da Silva ${ }^{4}$

[1, 2, 3, 4] Universidade Federal de Mato Grosso do Sul I Título abreviado: O Método Reno I Endereço para correspondência: Rua Marquês de Pombal, $\mathrm{n}^{\circ}$ 2520, Casa 143, Bairro Tiradentes, CEP: 79041080, Campo Grande - MS, Brasil I Email: naylamota@live.coml DOI: 10.18761/PAC.2016.037

\begin{abstract}
Resumo: Em 1957, Skinner publicou a obra “O Comportamento Verbal”, na qual aplicou os pressupostos do behaviorismo radical para uma explicação da relação verbal entre falante e ouvinte, dando ênfase especial na descrição do comportamento do falante. Desde então, tais premissas têm sido sistematicamente aplicadas à análise comportamental do discurso (ACD) e alguns importantes estudos têm se desenvolvido na área. O presente artigo tem por objetivo apresentar, didaticamente, o método de análise do discurso desenvolvido por Willard Day Jr. (1926-1989) e seus alunos, na Universidade de Nevada, no final da década de 1970. Para isso, propõe-se uma junção concisa, atualizada e prática de fases para a realização desse método. O Método Reno, como ficou conhecido, busca inter-relacionar, sob influência do movimento hermenêutico, o método experimental ao método interpretativo e tem se mostrado eficaz e interessante para a análise de relações verbais.
\end{abstract}

Palavras-chave: Método Reno, comportamento verbal, análise comportamental do discurso. 
Abstract: In 1957, Skinner published the book Verbal Behavior, in which he applied the assumptions of radical behaviorism on the explanation of the verbal relation between speaker and listener, especially emphasizing the description of the speaker. Since then, these assumptions have been systematically applied to the behavioral analysis of discourse (BAD) and some important studies have been developed in the area. This article aims to didactically present the discourse analysis method developed by Willard Jr. Day (1926-1989) and his students at the University of Nevada in the late 1970s. For this, it is proposed a concise, updated and practical combination of phases for the accomplishment of this method. The Reno Method, as it became known, intends to interrelate, under the influence of the hermeneutic movement, the experimental method to the interpretative method and has been shown effective and interesting for the analysis of verbal relations.

Keywords: Reno Method, verbal behavior, behavioral analysis of discourse.

Resumen: En 1957, Skinner publicó el libro Conducta Verbal, aplicando los supuestos del conductismo radical en la explicación de la relación verbal entre el hablante y el oyente, con especial énfasis en la descripción de comportamiento del hablante. Desde entonces, estos supuestos se han aplicado sistemáticamente al análisis conductual del discurso (ACD) y algunos estudios importantes han sido desarrolladas en esta área. Este artículo tiene como objetivo presentar de forma didáctica el método de análisis del discurso desarrollado por Willard Jr. (1926-1989) y sus estudiantes en la Universidad de Nevada a finales de 1970. Para ello, se propone un conjunto conciso, actualizado y práctico para lograr este método. El Método de Reno, como se hizo conocido, busca interrelacionar, bajo la influencia del movimiento hermenéutico, el método experimental para al método interpretativo y ha demostrado ser eficaz e interesante para el análisis de las relaciones verbales.

Palabras-clave: Método de Reno, conducta verbal, análisis conductual del discurso. 
O presente artigo foi escrito buscando atingir alguns objetivos no que se refere à divulgação do Método Reno como uma ferramenta para a realização de uma análise comportamental do discurso (ACD). Estabeleceu-se como meta delimitar, ainda que de forma introdutória, os pressupostos delineados pelos precursores do método, Willard Day Jr. (1926-1989) e colaboradores. Para isso, será descrito, de forma didática, o Método Reno, apontando-o como uma ferramenta de análise do comportamento verbal. Dado que a compreensão das relações verbais é fundamental para o trabalho do psicólogo nos mais diversos contextos de atuação, esperamos dar maior visibilidade a essa estratégia metodológica, apontando o Método Reno como uma opção efetiva para a realização de análises discursivas e que se mostra condizente com os pressupostos do behaviorismo radical. Buscamos, ainda, apontar que tal ferramenta deve ser considerada uma meta-análise, ou uma autodescrição do comportamento de analisar e que ao lidar com um discurso o analista vai lidar, antes, com seu próprio comportamento de responder ao material analisado.

Fenomenologia comportamental (ou Método Reno) é mais uma estratégia metodológica ou domínio metodológico do que uma abordagem tática específica. Eu entrei em contato com o trabalho de Willard Day, enquanto na graduação, no final dos anos 70, e estudei a longa distância com ele e seus alunos até a morte de Willard. Minhas raízes eram (e ainda são) firmemente plantadas na análise experimental do comportamento, mas este trabalho mudou tudo que eu havia feito desde então, e tudo o que eu pretendo fazer. É seguro dizer que Willard Day iniciou o estudo sério do sistema científico de Skinner, o behaviorismo radical, e é a partir desta perspectiva que as variações metodológicas começaram. Algumas longas histórias aqui, mas, basicamente, a metodologia é sobre trazer variações dos métodos interpretativo e experimental, para arcar diretamente com o comportamento humano complexo, onde quer que ele possa ser observado de forma sistemática, até mesmo em contextos relativamente naturalistas. (S. Leigland, comunicação pessoal, 13 de outubro, 2014)
Conforme apontado por S. Leigland (comunicação pessoal, 13 de outubro, 2014), o Método Reno tem como base os pressupostos do behaviorismo radical, e, mais especificamente, os princípios defendidos por Skinner (1904-1990) na obra "O Comportamento Verbal" (Skinner, 1957/1978). Foi nessa obra que Skinner definiu comportamento verbal como comportamento operante, que tem sua consequência mediada pela ação de outras pessoas. Ao descrever o que ocorre em uma interação verbal típica entre falante e ouvinte, explicitou que, tal qual os demais comportamentos operantes até então observados, o comportamento verbal pode ser definido de forma relacional, levando-se em consideração o efeito sobre o comportamento de um outro organismo, o ouvinte.

O foco de análise de Skinner (1957/1978) manteve-se direcionado ao falante, mas ao se analisar uma interação verbal deve-se considerar também o papel do ouvinte, já que se não houvesse um treino prévio pela comunidade verbal, o ouvinte não poderia responder efetivamente ao falante que interage com ele.

Em suma, é possível definir o termo comportamento verbal assim: trata-se de uma expressão que se refere ao comportamento de falantes individuais; que é modelado e mantido por consequências mediadas por ouvintes, ou por representantes da comunidade verbal, conforme as práticas de reforçamento dessa comunidade. (Abib, 1994, p. 476)

O comportamento verbal está, assim, sujeito à seleção pelas consequências, já que o ouvinte consequencia o comportamento do falante e o modela. Outra característica marcante da definição skinneriana fica a cargo da relação intrínseca estabelecida pelo autor entre a emissão verbal e o contexto no qual ocorreu a emissão. Isso quer dizer que o significado de uma resposta verbal está atrelado ao contexto no qual ocorreu a emissão, de tal forma que analisar uma resposta verbal fora do seu contexto significa torna-la incompreensível (Day, 1969).

É na relação indivíduo-ambiente que ocorre a construção dessa história de reforçamento do sujeito. Deve-se atentar que essa relação não se dá de forma linear, tampouco em uma relação 
de um para um, já que o comportamento verbal apresenta múltiplas fontes de controle (Moxley, 1999; Skinner, 1957/1978). Essa especificidade é também, por assim dizer, um complicador ao estudar o comportamento verbal, já que são várias as possibilidades de combinação e recombinação dos estímulos que podem controlar uma emissão verbal qualquer. Uma única resposta emitida pode ser função de mais de uma variável e, com frequência, uma única variável costuma afetar mais de uma resposta. Diz-se, portanto, que o comportamento verbal é multideterminado, assumindo-se que são inúmeras as variáveis que podem controlar a emissão de uma resposta verbal qualquer. Um aluno observando e registrando o comportamento de pressão à barra de um rato, em uma disciplina no laboratório, estará sob controle da teoria com a qual está trabalhando, da presença do seu professor que o observa durante a aula, do repertório pouco desenvolvido para aquela situação e da sua história prévia, só para citar algumas das possíveis variáveis que interferem no comportamento do aluno de registrar o comportamento de um rato.

Assim, uma emissão verbal pode ter como fonte de controle múltiplas variáveis e apresentar, por isso, diferentes significados. Na proposta de Skinner (1957/1978), o significado passa a ser entendido não mais como uma propriedade intrínseca da palavra, mas a partir da análise das contingências nas quais a emissão verbal está inserida (Córdova \& Medeiros, 2003). As circunstâncias que controlam determinada resposta verbal são, assim, o seu significado (Skinner, 1980) e, ao dizer que determinados comportamentos têm significados distintos, diz-se que estão sob controle de variáveis distintas (Skinner, 1969).

Sendo assim, ao buscar descrever as fontes de controle de um episódio verbal qualquer, deve-se delimitar quais os aspectos envolvidos nessa interação e descrever, sobre os eventos comportamentais, quais são seus antecedentes e consequentes (Skinner, 1957/1978). A resposta verbal passa a ser encarada como uma variável dependente em relação às condições ambientais historicamente estabelecidas nas quais ela ocorre. Dessa forma, assume-se que, no behaviorismo radical,
. . . a explicação do fenômeno não pode ser a descrição do fenômeno em si mesmo apenas, mas em suas relações com outros fenômenos ou eventos da natureza. É apenas nesse sentido que 'descrever é explicar', ou seja, no sentido de descrever relações entre variáveis e não apenas descrever características físicas ou morfológicas dos fenômenos. Daí surgirem as relações funcionais, onde o aparecimento de variáveis cujos valores se alteram simultaneamente (VI-VD), mas não necessariamente no mesmo sentido, sinaliza a existência de relações que podem ajudar a compreender fenômenos comportamentais. (Carrara, 2002, pp. 54-55)

Discriminar tais relações verbais, por meio da análise funcional, é entender o significado daquilo que foi dito (Day, 1969). Para proceder à análise de tais interações verbais, Skinner (1957/1978) estabeleceu categorias do comportamento verbal, denominadas operantes verbais, considerando para essa categorização as fontes de controle do comportamento verbal e o efeito sobre o ouvinte. Os operantes verbais de Skinner (1957) referem-se à descrição, na contingência tríplice, de variáveis controladoras antecedentes e consequentes de respostas verbais emitidas por um falante. $\mathrm{O}$ termo "verbal" indica que a resposta teve como consequência a resposta de um ouvinte (Hübner, 2012).

Skinner (1957/1978) propôs seis operantes verbais primários: tato, mando, ecoico, textual, transcrição e intraverbal, e um operante verbal secundário, o autoclítico. Essas definições serão retomadas ao descrever os passos de realização da análise com base no Método Reno. Não é, todavia, objetivo deste artigo descrever as particularidades de cada uma dessas categorias.

A proposta de Skinner (1957/1978) para comportamento verbal e o entendimento deste como comportamento operante, mediado por um ouvinte treinado por uma comunidade verbal, mostram-se relevantes ainda hoje para os behavioristas radicais. São vários os desdobramentos desses pressupostos em diferentes campos de atuação e dentre eles encontram-se aqueles autores que buscam entender as implicações dos princípios defendidos no behaviorismo radical para a análise comportamental do dis- 
curso (ACD) (Borloti, Iglesias, Dalvi, \& Silva, 2008; Borloti, 2004; Dougher, 1989; Leigland, 1989).

O discurso é, nesse campo científico, definido funcionalmente, ou seja, como um conjunto de operantes verbais com certas propriedades, emitido em um determinado contexto e sob controle de determinada audiência. Borloti, Iglesias, Dalvi \& Silva (2008) resumem algumas das características fundamentais do discurso, sob um viés analítico-comportamental:

... o discurso é o interesse do analista comportamental na $\mathrm{ACD}, 2)$ o discurso é determinado por contingências (passadas e atuais), 3) o discurso é um dado empírico e 4) sua análise se afasta da metafísica. Portanto, 5) a ACD é um procedimento de uma ciência natural que se propõe a prever e a controlar o discurso. (Borloti et al., 2008, p. 104)

A ACD mantém, assim, coerência com os princípios do behaviorismo radical, já que são as relações de controle que dão significado ao discurso. Por essa razão, na ACD, prioriza-se a análise histórica como chave de compreensão de uma emissão verbal. A ACD adota, então, como ferramenta interpretativa, a análise funcional do discurso, buscando conhecer quais as relações que controlam o falar (Borloti et al., 2008). Em contato com o discurso, o analista deve buscar descrever os antecedentes e consequentes de uma emissão qualquer e buscar categorizar tais emissões utilizando os operantes verbais descritos por Skinner (1957/1978). Esse é o método tradicionalmente utilizado pelos analistas do comportamento na análise do discurso.

Buscando trazer novos elementos à maneira de se analisar discursos sob um viés analítico-comportamental, encontra-se o trabalho desenvolvido por Willard Day Jr. e seus alunos na Universidade de Nevada. Conforme antecipado, o objetivo do artigo foi delimitar e descrever, de forma introdutória e didática os pressupostos do Método Reno. Para isso, foram analisados a proposta de Skinner (1957/1978) para a análise verbal e alguns artigos escritos por Day (1969) e por seus alunos (Dougher, 1989; Leigland, 1989) sobre o Método Reno. Buscamos, ainda, descrever em oito passos uma possibilidade de realizar a análise do discurso, com base no Método Reno. Para ilustrar tais passos, foram utilizados trechos do artigo publicado por Leigland (1989).

\section{Considerações iniciais sobre o Método Reno}

A proposta de ACD a ser discutida aqui, tem origem em um movimento filosófico-metodológico conduzido por Willard Day Jr. e seus alunos na Universidade de Nevada, Estados Unidos, no final da década de 1970. O Método Reno buscou, influenciado pelo movimento filosófico da Hermenêutica e pela Fenomenologia (Dougher, 1989), inter-relacionar o método experimental e o método interpretativo na análise dos dados e fortalecer a visão de que a interpretação é uma atividade essencial do behaviorista radical (Kohlenberg \& Tsai, 1991/2001).

Há, portanto, a busca pela superação da dicotomia sujeito-objeto na compreensão de um determinado fenômeno e é prioritariamente nesse sentido que se percebe uma aproximação entre os objetivos do behaviorismo radical e da fenomenologia (Day, 1969). O que se espera é entender determinado comportamento, verbal ou não, a partir da relação indivíduo-ambiente, buscando explicitar as fontes de controle sobre o comportamento emitido. A fenomenologia busca o significado da ação para o sujeito e o behaviorismo radical também. O behaviorista radical, todavia, o faz por meio da análise funcional.

Não se quer dizer, com isso, que o contexto social está excluído da análise. Entende-se, antes, que ele fica evidenciado na ação do indivíduo, que foi previamente exposto às contingências estabelecidas por uma comunidade que o ensinou e treinou, reforçando, por meio do ouvinte, determinados comportamentos, selecionando-os. A comunidade verbal atua estabelecendo as regras de ação para o indivíduo (Abib, 1994) e para entender o significado de uma ação qualquer, faz-se necessário entender a história de exposição às contingências a que ele foi submetido.

Assim, na pesquisa experimental que utiliza como ferramenta metodológica o Método Reno, espera-se manipular uma variável antecedente qual- 
quer, de acordo com os objetivos da pesquisa a ser desenvolvida, e observar como o sujeito de pesquisa responde, de forma pouco orientada e sem sugestão de respostas, diante do estímulo apresentado.

\begin{abstract}
Em pesquisa deste tipo, o pesquisador transcreve material verbal de interesse. O pesquisador, então, identifica, descreve e classifica aspectos do material verbal os quais têm efeitos similares sobre seu comportamento como leitor. Nesse sentido, classes de comportamento verbal são identificadas. $\mathrm{O}$ pesquisador, subsequentemente, faz avaliações em relação às variáveis que atuam no controle funcional do comportamento verbal, relacionando-o com aspectos de seu contexto ambiental histórico e atual. Estas avaliações estão diretamente sob o controle da experiência do pesquisador na observação do comportamento, da exposição repetida com os dados fornecidos na transcrição e do treino profissional como um membro da comunidade verbal científica associada com a obra de Skinner. (Bennett, 1988, citado em Dougher, 1989, p. 2)
\end{abstract}

Conclui-se, então, que a própria situação experimental é vista como estímulo discriminativo para as respostas de analisar do pesquisador. É uma autoavaliação realizada por ele com base no seu histórico de reforçamento, que inclui as práticas da comunidade verbal científica a qual ele pertence.

Apesar de o método experimental apresentar-se como o principal em pesquisas em análise do comportamento, mesmo em Skinner (1945) já se vê sugerido o uso da interpretação como método de análise na investigação científica de relações comportamentais, principalmente daquelas que apresentam um alto grau de complexidade e que, portanto, não seriam facilmente acessíveis ao método experimental.

Há que se sublinhar, todavia, que "a interpretação. . . está aqui subordinada ao arcabouço conceitual construído com o suporte da investigação empírico-experimental" (Tourinho, 2006, p. 4). Assim, a interpretação sendo norteada por conceitos analítico-comportamentais validados em investigação empírica, tem por base uma perspectiva relacional no estudo de eventos comportamentais complexos, não se remetendo, de modo algum, a descrições fisicalistas, mentalistas ou localizadas apenas no indivíduo.

É utilizada em situações que não atendem aos requisitos da análise e experimental e devem remeter-se "exclusivamente a relações funcionais identificadas previamente em análises experimentais se é para valerem como interpretações." (Tourinho, 2006, p.5).

Ao estabelecer tal método de análise do discurso, Day (1969) propõe ser necessário entender funcionalmente a emissão verbal do sujeito. $\mathrm{O}$ autor pontua que, a seu ver, conhecer o que levou alguém a dizer o que disse é entender, no sentido mais profundo, o que esse alguém disse. Isso é conhecer o significado da resposta verbal que está sob efeito tanto da história de reforçamento do sujeito quanto da contingência em operação. A descrição acurada de variáveis torna-se, então, parte essencial do fazer científico. Faz-se necessário, todavia, apontar que no behaviorismo radical essa descrição acurada não implica em assumir uma verdade absoluta e dogmática ou uma descrição da realidade tal qual ela se apresenta, tampouco a neutralidade teórica do cientista. Assume-se antes que:

\begin{abstract}
Os cientistas não chegam para o estudo do comportamento livres das suposições e pressuposições da cultura ao redor mas, sim, são, em parte, dirigidos por suas classificações conceituais, algumas das quais estão embutidas nas palavras que usamos regularmente para descrever o comportamento e nos padrões gramaticais da linguagem comum. (Chiesa, 2006, p. 34)
\end{abstract}

Os cientistas foram expostos a contingências reforçadoras que selecionaram seus comportamentos operantes, sendo treinados por uma comunidade verbal bem estabelecida. Entraram em contato com um arcabouço teórico prévio e aprenderam a comportar-se com base nesse referencial. Todas essas variáveis levam o cientista a ver o que vê, isto é, o que ele vê depende do que a sua experiência prévia lhe ensinou (Kuhn, 1996; Skinner, 1957/1978). O comportamento do cientista passa, desse modo, a ser ele mesmo objeto de estudo na análise do comportamento e, entendendo que "as palavras são o meio pelo qual os cientistas do comportamento 
expressam relações" (Chiesa, 2006, p. 37), faz-se necessário explicar o comportamento verbal científico, assumindo-o como modelado e mantido por suas consequências. Ora, o que se busca, então, por meio do Método Reno é a descrição sistematizada dos efeitos, sobre o analista, daquilo que é dito e discriminar quais as variáveis que controlam o comportamento deste em contato com o registro do discurso (Borloti et al., 2008).

Não se espera, dessa forma, ao se realizar tal análise, encontrar uma verdade dogmática e imutável sobre aquilo que foi dito. Mantém-se, antes, a defesa de uma posição antiontológica (Moxley, 1999), encontrada também em Skinner, já que ele:

\section{... rejeita a ideia de que, conhecendo-se algo sobre uma coisa, a expressão desse nosso co- nhecimento consista numa declaração sobre o quê aquele objeto do conhecimento é; a ideia de que esta coisa possa ter, de alguma forma, uma identidade permanente, como um ente real da natureza. (Kohlenberg \& Tsai, 1991/2001, p. 3)}

Decorre desse entendimento que a descoberta de verdades objetivas, como um ente real da natureza, não seria fundamental na efetividade da ciência behaviorista radical, um impacto significativo sobre a prática científica nesse campo. Tal atividade acabou destituída de um viés dogmático, passando a entender o fazer do cientista como um comportamento, em sua maioria verbal, controlado pelos mesmos tipos de variáveis que os outros comportamentos humanos complexos. Assim, passa a não ser possível enxergar a prática experimental de modo dissociado de uma postura interpretativa.

\section{Como fazer: aspectos metodológicos}

A seguir, será apresentado um passo a passo do Método Reno. Algumas das fases dispostas são executadas concomitantemente, porém, por questões didáticas, foram divididas e descritas separadamente em passos e em uma ordem específica. Tal modelo, por sua vez, foi embasado em materiais de autores tradicionais da área de $\mathrm{ACD}$ e, especifica- mente, do Método Reno (Bennett, 1988; Borloti, 2004; Borloti et al., 2008; Day, 1969; Dougher, 1989, 1993; Leigland, 1989; McCorkle, 1991).

Vários desses autores propuseram passos (ainda que de forma breve e resumida) em relação ao procedimento do pesquisador, em pesquisas com o Método Reno. Os passos divergentes propostos entre os autores (em diferentes momentos históricos) se complementam e, assim, a partir de uma compilação do material supracitado, é proposta uma junção concisa, atualizada e prática sobre as fases para a realização desse método de interpretação do comportamento verbal, desenvolvido por Willard Day e seus alunos. O estudo de Leigland (1989) foi o escolhido para ser usado como forma de ilustrar a prática de cada passo instrutivo, estudo empírico este considerado um dos pioneiros e mais importantes na construção e divulgação do Método Reno.

O experimento desenvolvido por Leigland (1989) buscou identificar as relações entre variações em esquemas de reforçamento sobre respostas de bicar de um pombo (Columba sp.) - variações ambientais - e o uso de termos mentalistas pelos participantes para explicar as respostas do pombo (variações de respostas verbais). Ele organizou dois experimentos, com a participação de sete estudantes universitários (no total), que assistiam a cada um desses experimentos executados ao vivo e forneciam explicações, por escrito, sobre o comportamento do pombo. Nos diferentes experimentos, o pombo era submetido a diferentes esquemas de reforçamento.

Para ser possível identificar as respostas do pombo que teriam controlado a resposta verbal do participante, o último recebia um interruptor de mão que apertava sempre que fosse registrar uma explicação para o comportamento observado. Assim, buscou-se identificar e relacionar as variáveis ambientais que controlavam as respostas verbais do participante.

A Figura 1 sintetiza os passos do Método Reno.

\section{$1^{\circ}$ passo - Arranjo das condições experimentais}

Primeiramente, é necessário criar condições experimentais que permitam avaliar o efeito de alterações ambientais (variáveis independentes) sobre 
1 - Arranjar condições experimentais que permitam avaliar - efeito đe alteraç̋̃es ambientais sobre respostas verbais dos participantes.

2 - Transcrever respostas verbais vocais dos participantes, de forma fidedigna à sua topografia.



3 - Selecionar segmentos verbais de interesse, agrupando os que compartilham uma função comum, a partir do efeito similar sobre o repertório do pesquisador.

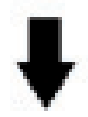

4 - Infenir os operantes verbais do discurso, identificando as relaçōes funcionais entre falante-ouvinte.

5-Criar e estabelecer categorias para os segmentos verbais dos participantes de acordo com seus efeitos sobre o repertóno do pesquisador.

6 - Analisar as variáveis ambientais (históricas e atuais) que controlaram funcionalmente o discurso.

7 -Descrever funcionalmente o próprio comportamento de analisar, discriminando verbalmente as variàveis que controlaram as análises feitas.

8-Expor-se repetidamente aos dados, de forma a discriminar análises novas e relevantes.

Figura 1. Passos do Método Reno. 
respostas verbais dos participantes (varáveis dependentes), pré-requisito fundamental para que uma análise funcional seja feita. Isso significa que, em um experimento orientado pelo Método Reno, determinados estímulos ambientais devem ser manipulados, medindo-se o efeito dessa manipulação sobre o comportamento verbal dos participantes.

Assim, em pesquisas que se utilizam desse método é necessário "criar medidas que constituam indicadores de variações nessas relações (indivíduo-ambiente) e não simplesmente de variações em ocorrências do próprio indivíduo" (Tourinho, 2006, p. 5). As varáveis ambientais escolhidas para serem manipuladas, bem como os tipos discursivos analisados, são diversas e variam de acordo ao problema de interesse da pesquisa. Também é necessária como condição experimental, a viabilização do registro do material verbal de interesse da pesquisa.

Ilustrando este primeiro passo, a partir do experimento desenvolvido por Leigland (1989): no Experimento I, o pombo era exposto a um esquema de intervalo fixo 4 minutos, com a chave constantemente iluminada na cor vermelha, com exceção do tempo em que o alimento era apresentado ao pombo (3 segundos). No Experimento II, a chave permanecia vermelha quando o comportamento do pombo era exposto a um esquema de tempo variável 1,5 minuto, e a luz se mantinha verde enquanto a apresentação de comida era mantida por uma razão fixa 12.

A partir desse arranjo experimental, o pesquisador pôde medir e identificar que o comportamento mantido sob controle de esquemas mais precisos e bem sinalizados (razão fixa) evocavam o uso de explicações mais descritivas, enquanto o uso de esquemas mais complexos (intervalo variável) favorecia a emissão de termos mentalistas.

\section{$2^{\circ}$ passo - Transcrição das respostas verbais vocais}

Em caso de respostas verbais vocais coletadas por meio de áudio ou vídeo (no que não consistiu o experimento de Leigland, devido às respostas verbais coletadas serem escritas pelos participantes), o próximo passo baseia-se na transcrição pelo pesquisador do material verbal vocal dos participantes. Tratando-se de respostas faladas, contribui também para a análise o registro das ênfases fei- tas, pausas, hesitações, erros na pronúncia, entre outras topografias de respostas observadas, que alteram o discurso. A transcrição deve ser o mais fidedigna possível em relação às respostas verbais dos participantes.

\section{$3^{\circ}$ passo - Isolamento/Agrupamento dos segmentos verbais de interesse}

No terceiro passo, depois de feita a transcrição de todo o material verbal (em caso de respostas vocais), segmentos desse material devem ser selecionados e isolados/agrupados para análise, conforme os efeitos dos mesmos sobre o pesquisador. Em outras palavras, o pesquisador (cujo repertório foi treinado em comunidade científica específica) avalia se o segmento é de interesse ao problema da pesquisa e quais segmentos compartilham uma função comum, que permite a apresentação de uma análise concisa e efetiva a partir de seu agrupamento. Em caso de mais de um pesquisador responsável, essa avaliação e análise deve ser consensual. Exemplos são: argumentos de defesa ou de crítica de um objeto qualquer, modos de descrição, formas de convencimento, indução de culpa, etc. (Borloti et al., 2008; McCorkle, 1991).

Detalhando um exemplo desta fase, no experimento de Leigland (1989), o pesquisador selecionou e isolou segmentos do material verbal coletado, numerando-os e colocando-os em gráficos. Esses gráficos relacionavam as respostas verbais do participante com o momento do experimento apresentado (qual esquema de reforçamento estava em vigor). Foram elaborados gráficos com os segmentos verbais, de cada participante, por condição experimental. Em texto, o autor mencionava o número correspondente ao segmento verbal e escrevia sua análise ao lado do segmento (que será apresentada a partir dos próximos passos).

A seguir, em caráter ilustrativo, é apresentado o segmento verbal correspondente ao sujeito 4 , na Fase Experimental II, quando o pombo era exposto à apresentação de comida mantida por razão fixa 12 e uma luz verde permanecia acesa: "6 - Mais uma vez a luz verde veio e ele bicou e, em seguida, ganhou algo para comer. Parece que ele pode sentir quando isso vai acontecer, porque ele primeiro olha para o buraco e daí bica" (Leigland, 1989, p. 14, tradução livre nossa). 
Alguns segmentos de um mesmo participante poderiam, no entanto, ser agrupados no texto, pois permitiam uma análise única por parte do pesquisador. Isso pôde ser observado, por exemplo, na análise de verbalizações referentes ao sujeito 3 , na Fase Experimental I, em que o pombo era exposto ao esquema de intervalo fixo (4 minutos). Nessa ocasião, o participante utilizou termos como "irritado", "chateado", "frustrado", "agressivo" e "bravo" (tradução livre nossa) para explicar o comportamento do pombo em seis momentos diferentes da Fase Experimental I. Os termos, por sua vez, apresentaram efeito semelhante sobre o repertório do pesquisador, que agrupou os segmentos em que eles apareceram (agrupou os números correspondentes a cada segmento) e elaborou uma análise comum para o conjunto desses segmentos.

\section{$4^{\circ}$ passo - Inferência dos operantes essenciais, elos intraverbais e estrutura autoclítica do discurso}

A identificação dos operantes verbais em um discurso (Borloti, 2004) é necessária para o alcance de uma compreensão inicial sobre as variáveis antecedentes e consequentes controladoras das respostas verbais apresentadas pelo falante. Operantes verbais são unidades funcionais, ou seja, dizem respeito a tipos de relações funcionais entre falante-ouvinte sob controle de alguma coisa ou acontecimento. Essas relações são melhor compreendidas quando se analisam os padrões de operantes verbais presentes no discurso.

No experimento de Leigland (1989), esta etapa de análise foi feita logo após a apresentação de alguns dos segmentos verbais selecionados (fase anterior). Como mencionado anteriormente, os segmentos estavam presentes em gráficos e cada um tinha uma numeração específica, que o autor mencionava (algumas vezes agrupados, como foi mostrado na fase anterior) e, então, fazia a análise dos operantes verbais ao lado. O exemplo a seguir, correspondente à análise de segmento verbal do sujeito 3 na Fase Experimental II (no momento em que o pombo era exposto ao esquema de razão fixa), ilustra este tipo de análise.

13 - "Eu sinto que ele está condicionado a esse teste". Tal como aconteceu com o sujeito 1 e 2 deste experimento, a maioria das 20 emissões verbais escritas do sujeito 3 consistiu do que poderia ser chamado de "tatos puros", no sentido de que as emissões são tipicamente bastante simples, diretas e descritivas. (Leigland, 1989, p. 13, tradução livre nossa)

\section{$5^{\circ}$ passo - Estabelecimento de categorias para o discurso}

Conforme o pesquisador vai repetidamente expondo-se aos dados nas fases anteriores, e considerando sua exposição já previamente orientada por uma demanda da pesquisa, estabelecem-se continuamente contingências (treino) para que o pesquisador crie categorias para classificar as respostas verbais coletadas ( $1^{\circ}$ passo), transcritas ( $2^{\circ}$ passo), isoladas/agrupadas ( $3^{\circ}$ passo) e das quais os operantes foram inferidos ( $4^{\circ}$ passo)

Essas categorias são estabelecidas a partir dos efeitos do material verbal do participante sobre o repertório do pesquisador, orientado pela problemática da pesquisa. $\mathrm{O}$ pesquisador agrupa respostas verbais de interesse que compartilham topografias ou funções comuns, ou seja, que apresentam efeitos semelhantes sobre seu comportamento de leitor.

Este passo é o que diferencia o Método Reno da proposta tradicional da ACD. No Método Reno, a postura interpretativa do cientista ganha mais força e espaço, sendo complementada por uma autoanálise. A respeito disso, Dougher (1993) afirma:

O método de Skinner envolve o isolamento de segmentos de comportamentos verbais e a inferência (1) dos seus operantes essenciais, (2) dos elos temáticos intraverbais surgidos do encadeamento desses operantes essenciais e (3) da estrutura autoclítica que envolve esses operantes. A hermenêutica comportamental complementa o método de análise dos segmentos verbais da seguinte maneira: o pesquisador deve ouvir e ler várias vezes o registro verbal (sonoro ou transcrito) buscando ocorrências do comportamento de interesse e os eventos antecedentes que parecem estar funcionalmente relacionados a ele. $\mathrm{O}$ pesquisador deve, em seguida, rever o dado para encontrar exemplos que confirmem a regularidade dessas relações. Depois, o pesquisador faz uma outra descrição funcional, só que do seu próprio 
comportamento ao conduzir o passo anterior, refinando as discriminações que fez. O terceiro passo envolve o agrupamento dos comportamentos de interesse em classes que compartilham funções comuns. O quarto passo é a descrição do comportamento de inferir do pesquisador, de modo a discriminar verbalmente quais amostras foram selecionadas e por quê. (pp. 216-217)

Esta fase dá ênfase à compreensão, em relação ao pesquisador, de que "o registro é o resultado de uma sutil distinção entre as variáveis que controlam o seu próprio comportamento como leitor ou ouvinte" (Skinner, 1957/1978, p. 452). Diante disso, no experimento de Leigland (1989), para a análise dos dados coletados, o pesquisador estabeleceu as seguintes categorias para o discurso dos sujeitos, de acordo com os efeitos sobre seu repertório: explicações mentalistas, explicações históricas e verbalizações que fizessem alusão à topografia de respostas. Segundo o autor, a discriminação de verbalizações interpretadas como mentalistas foi função do seu pertencimento a uma comunidade verbal da qual esse termo fazia parte.

Enquanto um procedimento deste tipo pode gerar comportamento verbal que poderia ser analisado em qualquer número de formas, o foco da análise foi "termos mentalistas" que possam ter ocorrido no contexto de tais declarações "explicativas". Pensou-se que a busca de ordem nos dados deveria começar com as dimensões comportamentais mais simples. Por conseguinte, a busca por ordem envolveu (1) a discriminação de uma classe de respostas verbais que poderiam ser identificadas como "termos mentalistas;" e (2) o mapeamento de tais respostas em discriminações de interações ambiente-comportamento sob observação, como traçado pelo registro cumulativo. (Leigland, 1989, p. 7 , tradução livre nossa)

Assim, primeiro, termos mentalistas foram identificados no discurso de cada participante e colocados em listas correspondentes aos participantes e às fases experimentais em que ocorreram. Em seguida, conforme na citação apresentada anteriormente, foi feito o mapeamento das variáveis am- bientais que controlavam essas respostas verbais, que consiste no próximo passo que será apresentado. Em suma, nesta fase, deve-se agrupar o material verbal de efeitos semelhantes (em categorias) para, na próxima etapa, buscar avaliar quais as variáveis dos contextos histórico e atual podem estar controlando tais verbalizações (Dougher, 1989).

\section{$6^{\circ}$ passo - Análise das variáveis (históricas e atuais) que atuam no controle funcional do discurso}

Como já discutido, Skinner (1957/1978), na obra "O Comportamento Verbal", inicia a proposta de que, assim como na análise de qualquer outro tipo de comportamento operante, entender o significado do discurso é conhecer quais variáveis o controlam (Day, 1969). Isso quer dizer que o discurso só é compreendido quando se compreende a história de reforçamento e as variáveis de controle atuais do mesmo, bem como os efeitos da manipulação desse ambiente sobre o discurso. Analisar funcionalmente o discurso é analisar a combinação de variáveis que atuam sobre o discurso.

Diante disso, nesta fase, são analisados os efeitos de variáveis experimentais sobre os discursos dos participantes, como por exemplo: características e comportamento da audiência; modificação de audiência; presença do pesquisador; condições artificiais da pesquisa; manipulação de variável ambiental, dentre tantas outras possibilidades de fatores.

Levando em conta que, segundo Borloti et al. (2008), "enunciados. . . são produzidos em contextos específicos e, portanto, reveladores de condições histórico-sociais que lhes dão força” (p. 102), também são analisados os efeitos de variáveis dispostas no contexto histórico dos participantes as quais se tem acesso. A análise das variáveis atuais sobre o discurso implica sempre em uma análise das variáveis históricas, pois as primeiras atuam em função de uma história de reforçamento em meio ao ambiente cultural.

. . . uma resposta verbal a uma situação não é o significado, e tampouco é a própria situação; então, uma resposta verbal a uma situação é uma relação que significa uma outra relação. . . Assim, uma relação atual entre uma resposta verbal e uma situação significa uma outra re- 
lação que é a história de contingências de reforçamento, isto é, o significado - responsável pela instanciação daquela relação no presente. Nesse sentido, o comportamento verbal é sempre significativo e é sempre explicado por significados - mesmo que desvelá-los não seja tarefa simples. (Abib, 1994, p. 485)

É importante enfatizar, todavia, que a realização da análise de variáveis não se dá necessariamente como um sexto passo, mas, sim, pode-se dizer que se dá de forma mais intensa e profunda neste passo, pois a própria classificação do material verbal em categorias estabelecidas pelo pesquisador e em operantes verbais é feita com base na identificação de variáveis externas que possam estar exercendo controle sobre as respostas verbais. Portanto, a análise das variáveis controladoras que atuam sobre as respostas verbais dos participantes é feita pelo pesquisador durante todo o processo de exposição aos dados, inclusive na análise dos operantes verbais e na classificação em categorias do discurso.

Dessa maneira, a partir deste método, é possível identificar diante de que contingências, o sujeito emite um determinado tipo (classe) de verbalização, ou seja, quais formas de interação ambiente-resposta estão exercendo controle sobre o comportamento verbal do indivíduo. Partindo disso, é possível formular hipóteses sobre as possíveis funções que mantêm as diferentes formas de verbalização.

Leigland afirma, assim, que o método "de fato torna certas relações de controle visíveis a respeito do comportamento verbal, mesmo quando a 'dimensão do estímulo’ é representada por algo tão simples e bidimensional como um registro cumulativo de um pombo" (Leigland, 1989, p. 17, tradução livre nossa). No experimento do autor, esta fase pode ser observada nas análises após os segmentos verbais selecionados, como no exemplo a seguir (análise de Leigland [1989] ao segmento do sujeito 4 , que fora foi apresentado no terceiro passo):

6 - "Mais uma vez a luz verde veio e ele bicou e, em seguida, ganhou algo para comer. Parece que ele pode sentir quando isso vai acontecer, porque ele primeiro olha para o buraco e daí bica." Parece que "pode sentir" é controlada em parte pela observação de controle de estímulo diferencial da resposta de bicar a chave e em parte pelo controle exercido pelas contingências (talvez temporais) em relação a outros aspectos do comportamento do pombo. (Leigland, 1989, p. 14, tradução livre nossa)

Ao analisar um discurso, então, o pesquisador (analista do comportamento) identifica e conjectura um conjunto plausível de circunstâncias que atuam sobre as respostas verbais e, principalmente, lida com o próprio comportamento de responder ao discurso (Skinner, 1957/1978). Entendendo, pois, que:

$\mathrm{O}$ treino profissional de behavioristas radicais leva-os a trazer para a observação direta do comportamento um tipo particular de aparato conceitual, o qual tem por principais características: a) a tendência a, valendo-se da observação do comportamento, evitar mentalismos; e b) o foco nas variáveis ambientais conforme elas agem no controle do comportamento. (McCorkle, 1991, p. 7, tradução livre nossa)

A próxima etapa consiste em tornar mais clara essa postura interpretativa do cientista, enfatizando que o mesmo não atua em função de uma "verdade absoluta", mas em função de um histórico de reforçamento e princípios específicos reforçados por uma determinada comunidade científica.

\section{$7^{\circ}$ passo - Descrição do próprio analisar} Após a categorização e análise funcional das verbalizações, o pesquisador deve fazer uma descrição funcional da sua própria resposta de categorizar/ analisar. Em outras palavras, o pesquisador discrimina verbalmente por que determinadas amostras foram selecionadas e classificadas em determinadas categorias e o que embasou tais análises (como, por exemplo, bases teóricas, experimentação, observação, experiência pessoal, experiência profissional, etc.).

Durante o procedimento, $\mathrm{o}$ analista deve fazer-se algumas perguntas, quantas vezes forem necessárias, até que obtenha, por fim, uma interpretação satisfatória. Pode perguntar-se, por um exemplo: "Como o falante me parece aqui?" (Borloti et al., 2008, p. 106). Aquele que analisa o discurso deve 
descrever esse caminho de perguntas e respostas que foi por ele trilhado na busca da interpretação, de tal modo que ela possa ser corroborada a posteriori por outros analistas. Assim, o foco da análise do discurso deve estar em como as variáveis ambientais agiram para controlar o comportamento do analista ao proceder à análise, buscando autodescrever o comportamento de analisar.

... quando nós estudamos [registros verbais], estudamos os efeitos dos registros... sobre nós. ... É o nosso comportamento em relação a tais registros o que nós observamos.... Assim, a compreensão do registro é o resultado de uma sutil distinção entre as variáveis que controlam o seu próprio comportamento como leitor ou ouvinte. (Skinner, 1957/1978, p. 452)

No estudo de Leigland (1989), o autor menciona diversas vezes o fato de seu próprio comportamento de categorizar e analisar ser função de sua história de reforçamento (como demonstrado em citação no quinto passo). No entanto, é no artigo de Dougher (1989), denominado "Uma análise funcional da análise funcional de um analista do comportamento" (tradução livre nossa), que ficam mais evidenciadas e especificadas as fontes de controle que atuaram sobre as análises de Leigland (1989), quando Dougher (1989) analisou o comportamento de Leigland (1989) de analisar.

O artigo de Dougher (1989) foi originalmente apresentado, juntamente ao de Leigland (1989), no Simpósio de 1984 da Associação de Análise do Comportamento (Association for Behavior Analysis). O Simpósio contou com Willard Day como debatedor, sendo seu propósito utilizar os trabalhos feitos, como uma base demonstrativa do que vinha sendo chamado de Método Reno (Leigland, 1989). No trabalho de Dougher (1989), o autor seleciona e agrupa descrições emitidas por Leigland e classifica as fontes de controle que atuaram sobre suas verbalizações, como, por exemplo, "história e treino como analista do comportamento" (p. 20, tradução livre nossa), "eventos relatados pelos sujeitos, mas não no registro cumulativo" (p. 20, tradução livre nossa), "eventos no registro cumulativo" (p. 20, tradução livre nossa), entre diversas outras variáveis.

\section{$8^{\circ}$ passo - Exposição repetida aos dados}

Este passo foi aqui colocado separadamente para que uma atenção especial fosse dada a ele, porém não ocorre somente como etapa final, mas ao longo de todo o processo. Durante toda a exposição do pesquisador aos dados, as leituras dos segmentos verbais devem ser feitas repetidamente, tanto antes do estabelecimento de categorias para os mesmos quanto durante a escrita da análise e depois da análise feita (uma vez que a repetição da exposição aos dados poderá indicar algo até então não observado, ou um equívoco, e direcionar a análise para novos caminhos).

McCorkle (1991) sintetiza esta fase na passagem:

A exposição repetida e cuidadosa do pesquisador a um material verbal é feita em grande parte com o propósito de moldar o seu comportamento discriminativo e de influenciar seu comportamento verbal subsequente. ... A função adaptativa da observação direta do comportamento verbal pelo pesquisador consiste no efeito da mesma de moldar discriminações novas, profissionalmente relevantes, no comportamento do pesquisador. A obrigação profissional primária do pesquisador que adquiriu novos repertórios discriminativos como resultado da observação direta do comportamento não é mais que simplesmente responder verbalmente sob o controle do que foi observado. (p. 7, tradução livre nossa)

Leigland (1989), nessa mesma direção, afirma que a repetida exposição aos dados teve o efeito de refinar seu próprio repertório discriminativo de analisar funcionalmente o comportamento verbal.

\section{Considerações finais}

Este artigo buscou fornecer os fundamentos para a realização da ACD, utilizando-se como ferramenta metodológica o Método Reno. Tal método, como anteriormente salientado, busca evidenciar a indissociabilidade entre o método experimental e o método interpretativo. Utiliza-se, para tal, como base, a proposta de Skinner (1957/1978) para análise do comportamento verbal; todavia, novos importantes elementos são apontados para que se possa chegar 
à compreensão do que levou alguém a dizer o que disse e da forma como fez.

No que se refere à aplicação da análise do comportamento, as ideias de Day exerceram marcada influência na construção da Psicoterapia Analítica Funcional (Kohlenberg \& Tsai, 1991/2001). No que se refere à experimentação, a análise do discurso com o Método Reno tem se mostrado efetiva e alcançado resultados interessantes quanto ao maior conhecimento de contingências envolvidas em relações verbais, implicando também o papel do pesquisador na análise feita, apesar de ser, sabidamente, uma ferramenta metodológica ainda de uso pouco difundido.

Nesse sentido, salienta-se que o conhecimento sobre o método interpretativo-experimental do discurso possibilita a compreensão das relações verbais presentes nas mais diferentes situações que o analista do comportamento se proponha a pesquisar (talvez, ainda, em condições artificiais). Isso possibilitaria, por sua vez, além de uma explicitação de contingências, interessantes intervenções sobre relações verbais, dado os princípios éticos e de eficiência que orientam a análise do comportamento.

Assim, é aqui proposto que o Método Reno seja aplicado em contextos mais variados, a fim de proporcionar um maior conhecimento sobre discursos nos diversos âmbitos em que o psicólogo atua, visto que este lida predominantemente com comportamento verbal. No entanto, alguns pontos ainda se apresentam como complicadores para o uso de tal ferramenta. O próprio Day pouco publicou sobre tal proposta e os estudos publicados à época foram desenvolvidos por seus alunos. Há, ainda, o desafio, para os pesquisadores que se interessem por esse método, de encontrar formas de arranjos experimentais que permitam a observação de relações verbais em contextos naturalistas.

Espera-se, então, com este artigo provocar algumas reflexões sobre a relevância dessa ferramenta para ACD sob um viés analítico-comportamental e fomentar o interesse pelo desenvolvimento de novas pesquisas, inclusive em contextos extra-laboratoriais e a respeito de problemáticas socialmente relevantes, que busquem dar maior sustentação teórico-empírica ao seu uso.

\section{Referências}

Abib, J. A. D. (1994). O contextualismo do comportamento verbal: A teoria Skinneriana do significado e sua crítica ao conceito de referência. Psicologia: Teoria e Pesquisa, 10(3), 473-487.

Bennett, M. (1988, setembro). The Renomethodology: A short description. Trabalho apresentado no Radical Behavioral Retreat, Glenbrook, NV, Estados Unidos.

Borloti, E. (2004). As relações verbais elementares e o processo autoclítico. Revista Brasileira de Terapia Comportamental e Cognitiva, 6(2), 221-236.

Borloti, E., Iglesias, A., Dalvi, C. M., \& Silva, R. D. M. (2008). Análise Comportamental do Discurso: fundamentos e método. Psicologia: Teoria e Pesquisa, 24(1), 101-110. doi: 10.1590/ S0102-37722008000100012

Carrara, K. (2002). O mito da síntese experimental do comportamento: reflexões a partir do Behaviorismo Radical e do Contextualismo pepperiano (Tese de livre-docência). Recuperado de https://repositorio.unesp.br/handle/11449/116084

Chiesa, M. (2006). Behaviorismo Radical: A filosofia e a ciência. Brasília: IBAC.

Córdova, L. F., \& Medeiros, C. A. (2003). Diferenciação entre a noção de significado pelo uso e a baseada em relações de equivalência. Em M. Z. da S. Brandão, F. C. de S. Conte, F. S. Brandão, Y. K. Ingberman, C. B. de Moura, V. M. da Silva, \& S. M. Oliane (Orgs.), Sobre comportamento e cognição: A história e os avanços, a seleção por conseqüências em ação (Vol. 11, pp. 170-178). Santo André: ESETec.

Day, W. F. (1969). Radical behaviorism in reconciliation with phenomenology. Journal of the Experimental Analysis of Behavior, 12(2), 315328. doi: 10.1901/jeab.1969.12-315

Dougher, M. J. (1989). A functional analysis of a behavior analyst's functional analysis. The Analysis of Verbal Behavior, 7, 19-23.

Dougher, M. J. (1993). Interpretative and hermeneutic research methods in the contextualistic analysis of verbal behavior. Em S. C. Hayes, L. J. Hayes, H. W. Reese, \& T. S. Sarbin (Orgs.), The 
Varieties of Scientific Contextualism (pp. 147159). Reno, NV: Context Press.

Hübner, M. M. C. (2012, maio). Operantes Verbais de Skinner: definição e identificação na clínica e no cotidiano. Curso ministrado no I Congresso Brasileiro de Terapia por Contingências de Reforçamento, Campinas, SP. Recuperado de http://www.congressobrasileirotcr.com.br/resumos/cursos/martha.pdf

Kuhn, T. (1996). A estrutura das revoluções científicas. São Paulo: Editora Perspectiva.

Kohlenberg, R., \& Tsai, M. (2001). Psicoterapia analítica funcional: criando relações intensas e curativas. Santo André: ESETec. (Trabalho original publicado em 1991.)

Leigland, S. (1989). A functional analysis of mentalistic terms in human observers. The Analysis of Verbal Behavior, 7, 5-18.

McCorkle, M. (1991). A Retrospective Account of Some Qualitative Research. The Qualitative Report, 1(2), 1-10.

Moxley, R. A. (1999). The two Skinners, modern and postmodern. Behavior and philosophy, 27, 97-125.

Skinner, B. F. (1945). The operational analysis of psychological terms. Psychological Review, 52(5), 270-277. doi: 10.1037/h0062535

Skinner, B. F. (1969). Contigencies of reinforcement. New York: Appleton-Century-Crofts.

Skinner, B. F. (1978). O comportamento verbal. São Paulo: Cultrix. (Trabalho original publicado em 1957.)

Skinner, B. F. (1980). Notebooks. Englewood Cliffs, NJ: Prentice-Hall.

Tourinho, E. Z. (2006). Relações comportamentais como objeto da Psicologia: algumas implicações. Interação em Psicologia, 10(1), 1-8. doi: 10.5380/psi.v10i1.5792

\section{Informações do Artigo}

Histórico do artigo:

Submetido em: 05/10/2016

Primeira decisão editorial: 10/02/2017

Aceito em: 13/04/2017 